\title{
THE DISAPPEARANCE OF SULPHEMOGLOBIN FROM THE BLOOD OF TNT WORKERS IN RELATION TO THE DYNAMICS OF RED CELL DESTRUCTION
}

\author{
BY
}

\author{
E. M. JOPE \\ From The London Hospital
}

Preliminary studies of the rates of disappearance of Methemoglobin (MHb) and Sulphemoglobin (SHb) from human blood in vivo after cessation of contact with the agents, such as sulphonamides, acetanilide or TNT, causing these abnormal pigments (Jope and O'Brien (1942): Jope, O'Brien and Watson (1942)), revealed a striking contrast between $\mathrm{MHb}$ and $\mathrm{SHb}$ in this respect. MHb was found to disappear rapidly from the circulating blood and was undetectable after 2 to 5 days from removal of the causative agent ( $c f$. also Cox and Wendel (1942) ), whereas SHb was found to persist and was still detectable after many weeks. Methemoglobin also disappeared rapidly from drawn blood, being usually no longer detectable after about 24 hours at room temperature (Jope and O'Brien (1942) ). Hence the persistence of $\mathrm{MHb}$ in the body during administration of the causative agent must be due to the interaction of two competing processes, the formation of $\mathrm{MHb}$ by interaction probably with some metabolite of the sulphonamide or TNT, and the reversion of $\mathrm{MHb}$ back to functional hemoglobin, a reduction of the ferric iron atom, which several workers have shown to be coupled to the intracellular reduction processes such as glycolysis, and to be inhibited by fluoride or iodoacetate ions (Warburg et al. (1930, 1931): Wendel (1933): Cox and Wendel (1942): and Drabkin (1945) ). SHb, on the other hand, may be kept unchanged in drawn blood even longer than the red cells can be kept intact, and remains for several weeks after hemolysis as a constant fraction of the total pigment present, so long in fact as the blood can be kept sterile. It appears, therefore, that the red cell has no mechanism within it for the transformation of SHb. If this is so, the body can have no means of removing SHb other than by destruction of the red cells that contain it.

The disappearance of sulphemoglobin in vivo was therefore studied in some detail, both in order to gain a more precise knowledge of the conditions necessary for recovery from $\mathrm{SHb}$ cyanoses, and as a possible means of studying the dynamics of red cell destruction.

\section{Material and Methods}

Material. Seven TNT workers whose blood contained more than 4 per cent. of total pigment as $\mathrm{SHb}$ were selected for the experiment. Of those, 3 males and 2 females with an age range of 30 to 50 appeared to have no reaction to TNT contact other than cyanosis and could be regarded otherwise as normal healthy individuals. The other 2 males exhibited a more marked reaction to TNT after only a few weeks of contact. One was a man of $\mathbf{4 0}$ with a history of malaria and dysentry. His liver was enlarged, but had been so for many years. The other was a man of 60 who in 4 weeks' contact developed nausea and vomiting, dyspnoea and cyanosis ( $\Delta$ in fig. 2 ). During this period he developed an enlarged liver. His hemoglobin was low, being 70 per cent. (Haldane) and fell to 68 per cent. during his first four weeks off contact, but subsequently rose reaching 80 per cent: by the end of the $3 \frac{1}{2}$ months of the experiment. 100 per cent. Haldane as used here is defined in Macfarlane, O'Brien et al. (1944).

These workers were removed from contact with TNT and put on to light work for the duration of the experiment. Blood was collected by venepuncture using potassium oxalate as anticoagulant. Some initial semi-quantative examinations for abnormal pigments were made at the factory but the stability of SHb made this unnecessary during the experiment, and later samples were sent by passenger train or express post, being examined always within 24 hours of venepuncture, and often much sooner. This rapidity of transport is of course much more important when $\mathrm{MHb}$ is being studied, but the use of blood sugar bottles containing fluoride to inhibit glycolysis should be helpful in these cases.

\section{Estimation of Sulphemoglobin}

This has been carried out from the spectral absorption curves of dilutions of the bloods in $\mathbf{0 . 1}$ per cent. sodium chloride, which were thoroughly cleared by centrifugation. (In determining $\mathrm{MHb}$ a buffer must be used as the absorption curve is very sensitive to small variations in $\mathrm{pH}$ (e.g. Austin and Drabkin (1935): Jope (1941) ).

\section{Preparation of Blood Dilutions for Spectrophoto- metry}

It is necessary to take the greatest care in obtaining perfectly transparent blood dilutions for spectrophotometry. if $\mathrm{SHb}$ and $\mathrm{MHb}$ are to be estimated with any accuracy. This is particularly important when estimating small amounts, such as those encountered towards the end of the experiment, when results from slightly turbid solutions would have been of little value. From dilutions of 
abnormal bloods it is often particularly difficult to remove the turbidity completely and Horecker (1944) has shown that the formation of $\mathrm{MHb}$ in the blood of men and cats by the action of TNT or related substances may be accompanied by the accumulation of denatured globin within the red cells, giving persistent turbidity on dilution. Although much turbidity can be avoided by using an alkaline diluent such as 0.1 per cent. sodium carbonate, in the present work it has been desirable to work in more neutral solutions as some abnormal blood pigments are less stable and their spectral absorption less marked in alkaline solutions. Accordingly, vigorous centrifugation of 0.1 per cent. sodium chloride dilutions has been used. Ten minutes spinning at 20,000 r.p.m. using an International high-speed head, which had previously been chilled in acetone- $\mathrm{CO}_{2}$ has been found most satisfactory, though most dilutions can be cleared by spinning in an angle centrifuge for 20 minutes or less at 9000 r.p.m. At 6000 r.p.m. 40 to 60 minutes is often necessary, when heating effects become troublesome. The 0.1 per cent. sodium chloride diluent contained 0.5 per cent. sodium oleyl sulphate (MMB) to ensure complete hemolysis.

\section{Spectrophotometry}

The spectral absorption curves were obtained with a Hilger medium quartz spectrograph E498, and spekker photometer, using a 108-watt Tungsten ribbon filament lamp as a light source. Ilford panchromatic plates (H \& D 500) were used, having an upper wavelength limit of sensitivity about $\lambda=660 \mathrm{~m} \mu$. Kodak IIIF emulsion is sensitive up to $690 \mathrm{~m} \mu$. A photo-electric microphotometer was used to observe the wavelength of the match points on the plates.

For the absorption curves in the red beyond $\lambda=$ $600 \mathrm{~m} \mu \cdot 1 / 25,1 / 10$ or $1 / 5$ dilutions of whole blood were examined in $5 \mathrm{~cm}$., $1 \mathrm{~cm}$., or $0.5 \mathrm{~cm}$. cells respectively. For the range $\lambda=450-600 \mathrm{~m} \mu$, $1 / 25$, dilutions were examined in $0.5 \mathrm{~cm}$. cells. Under these conditions a blood containing 5 per cent. of its pigment as SHb gives extinction coefficients of about 1.3 at $540 \mathrm{~m} \mu$ and 0.8 at $620 \mathrm{~m} \mu$.

The amounts of $\mathrm{HbO}_{2}$ ( $x$ grams per cent.) and $\mathrm{SHb}$ ( $y$ grams per cent.) in the whole blood may be calculated from expressions (1) and (2).

grams per cent. $\mathrm{HbO}_{2}$,

$$
x=0.122 \mathrm{E}_{540}-0.0965 \mathrm{E}_{620} .
$$

grams per cent. $\mathrm{SHb}$,

$$
y=0.13 \mathrm{E}_{620}-0.00029 \mathrm{E}_{540}
$$

where $E_{540}$ and $E_{620}$ are the extinction coefficients of the whole blood at $\lambda=540$ and $620 \mathrm{~m} \mu$, i.e. observed optical density $\times$ dilution of whole blood cell thickness in cms.

From these values of $x$ and $y$ the percentage of total pigment in the form of SHb may be calculated from the expression :

$\mathrm{SHb}$, percentage of total pigment $=\frac{y}{x+y} \times 100$

The constants in (1) and (2) must necessarily be fixed somewhat arbitrarily, as it is impossible to obtain a solution containing pure SHb uncontaminated with other absorbing pigments. For the particular purpose of this paper, however, uncertainty in the absolute amount of SHb present is not a serious limitation, for it is only necessary to follow the disappearance of the SHb band at $\lambda=620 \mathrm{~m} \mu$. It is possible from the constants used in (1) and (2) to give the clinician a reasonable estimate of the non-oxygen combining pigment present. Drabkin and Austin (1935) first attempted to define the spectral constants of SHb, but Lemberg, Holden, Legge and Lockwood (1942) have since shown that some choleglobin is formed simultanteously with $\mathrm{SHb}$ by the action of $\mathrm{H}_{2} \mathrm{~S}$ and oxygen on hemoglobin, and as Drabkin and Austin did not take this into consideration, their estimate of the extinction coefficient of $\mathrm{SHb}$, E mol. $(\lambda=620 \mathrm{~m} \mu)=10,600$, was probably too low.* Lemberg et al. (1942) studied the spectral absorption of SHbCO and from their data a value $\mathrm{E}$ mol. $(\lambda=617 \mathrm{~m} \mu)=16,000$ may be calculated.

In the present work, where in some cases there were reasons for avoiding the CO-derivatives, a value for SHb, E mol. $(\lambda=620 \mathrm{~m} \mu)=13,000$, was derived from the data of Lemberg et al. by determining the relation between the spectral absorption of bloods containing $\mathrm{SHb}$ and the same after conversion to $\mathrm{HbCO}+\mathrm{SHbCO}$, and this value has been used in the derivation of (1) and (2). Some confirmation of the spectrophotometric estimates of non-oxygen combining pigment present in two bloods containing SHb was obtained by comparison of iron analyses and oxygen combining powers (Jope, Jope and O'Brien, (1944)). The spectral absorption of SHb both in the visible and UV requires further study, as the results found in this preliminary study do not agree in detail with some reported in the literature (Drabkin and Austin (1935): Michel (1938): Lemberg et al. (1942) ).

\section{The Process of Formation and Nature of Sulphemo-} globin

By the action of $\mathrm{H}_{2} \mathrm{~S}$ and $\mathrm{O}_{2}$ on hemoglobin, a compound is formed with a spectral absorption band at $\lambda=620 \mathrm{~m} \mu$, the position of which is comparatively insensitive to changes in $\mathrm{pH}$, and to many reagents such as $\mathrm{KCN}$ or ammonium sulphide, which affect the spectrum of MHb. The band is, however, shifted to $\lambda=617 \mathrm{~m} \mu$ by the action of CO. The identification of this pigment with clinically encountered $\mathrm{SHb}$ rests upon the appearance in the spectrum of the latter of a similarly stable band at $\lambda=620 \mathrm{~m} \mu$, similarly shifted to $\lambda=617 \mathrm{~m} \mu$ by treatment with $\mathrm{CO}$. Both the artificial and natural pigments are unstable in $0.05 \mathrm{~N}$ sodium hydroxide.

The process of $\mathrm{SHb}$ formation in vivo is not known, though it probably involves an oxidation and Michel (1938) has shown that at any rate in vitro the presence of soluble sulphides are necessary as a source of SH. The factors which favour SHb

*E mol. as used for heme pigments is defined as the molar extinction of a solution containing 1 gram atom of iron per litre, i.e. in the case of hemoglobin for a molecular unit of 17,000 . 
rather than $\mathrm{MHb}$ formation following ingestion of a large variety of amino- or nitro-benzene derivatives are quite unknown; $\mathrm{SHb}$ is most commonly observed clinically and in animals after acetanilide or phenacetin ingestion. With TNT or sulphonamides the number of cases in which $\mathrm{SHb}$ is found is about 2 per cent. of those in which $\mathrm{MHb}$ is observed.

The constitution of $\mathrm{SHb}$ is still uncertain, and many of the difficulties in elucidating it arise from the inability to produce the pigment in pure form (Lemberg et al. (1942) ). That the general character of the protein in $\mathrm{SHb}$ is the same as that of the oxyhemoglobin from which it is formed is indicated by the electrophoretic homogeneity of the two pigments as shown by Michel (1938), and it has been found impossible so far to separate them by chromatography (Jope, Jope and O'Brien (1944)). Michel (1938) found it impossible to separate rat or dog $\mathrm{SHb}$ from oxyhemoglobin by crystallization, though Lemberg et al. (1942) have achieved such a separation in the case of $\mathrm{SHb}$ formed by sulphur and acetanilide ingestion in rats. The change in absorption spectrum indicates that the chief differences between $\mathrm{SHb}$ and $\mathrm{HbO}_{2}$ may be expected in the heme group. It seems clear now that the prophyrin ring structure is unbroken in SHb (Lemberg et al. (1942): Jope (1941)). Haurowitz (1940) found that acid hydrolysis or peptic digestion of $\mathrm{SHb}$ did not give a separation of the heme group from the protein as it did with hemoglobin itself, but gave a compound with much protein material still attached to the heme, which he called Sulpheminproteose. From further drastic degradation experiments he suggested that some earlier findings of Haurowitz was due to the presence of free sulphir in the latter's product, which was eliminated cataphoretically by Michel.

$\mathrm{SHb}$ can combine quantitively with $\mathrm{CO}$ (Michel (1938): Jope, Jope and O'Brien (1944)) and the central iron atom appears to be in the ferrous state, which may also be concluded from Keilin's (1933) demonstration of the existence of Sulphmethemoglobin.

\section{Results \\ Disappearance of SHb in vivo}

The results from the study of the seven TNT workers are shown in fig. 2. To reduce all the data to a comparable vertical scale, the SHb has been plotted as the percentage of the amount present on the day the worker was removed from contact with TNT, the time, $t$, is in days subsequent. From all the data the regression of $\mathrm{SHb}$ on time has been calculated as

$$
\mathrm{SHb}=96-0.83 t \quad . \quad . \quad . \quad \text { (4). }
$$

The actual levels of $\mathrm{SHb}$ encountered in these workers during contact with TNT were between 4 and 7 per cent. of total blood pigment. The observation of Lemberg et al. (1942) that no choleglobin was detectable in clinical sulphemoglobinemia was confirmed in the present work.

\section{Disappearance of MHb in vivo}

The disappearance of $\mathrm{MHb}$ from the blood of a TNT worker who developed cyanosis soon after contact with TNT is shown by the broken line in fig. B. 12 per cent. of his total pigment was in the form of $\mathrm{MHb}$ at the end of contact, and $\mathrm{MHb}$ was no longer detectable five days later.<smiles>C=CC1=C(C)C(C)=NC1=CC</smiles><smiles>C=CC1C(C)=C2N=C(C)C(C)C1C2(O)O</smiles>

FIG. 1.

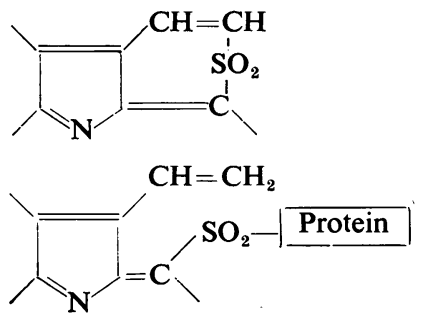

two $-\mathrm{SO}_{2} \mathrm{H}$ groups had become attached to two of the methene bridges of each porphyrin ring and that subsequent condensation had taken place with the vinyl groups. This does not account for the strengthened linkage between the heme and the protein. A possible explanation of this might, however, be found in a condensation with loss of water taking place between the $-\mathrm{SO}_{3} \mathrm{H}$ and a basic group of the protein (fig. 1).

Michel (1938) found one extra $S$ atom per Fe atom in SHb but Haurowitz (1940) found two, and made the suggestion that a compound with the same spectral absorption would result whether one or two methene bridges of the porphyrin ring were substituted. This is improbable. Michel considered that the discrepancy between his results and

\section{The Stability of Sulphemoglobin}

In order to test the stability of intracellular SHb attempts were made to store bloods from some of these workers in an incubator at $37^{\circ} \mathrm{C}$. Great difficulty was experienced in keeping the bloods sterile for more than a few hours under these conditions, as the addition of any sterilizing agent might have inhibited any intracellular enzyme which could transform SHb. Some success was, however, achieved in two experiments, though even here much MHb had been formed and over 80 per cent. of the red cells had been hemolysed by the end of ten days. The presence of MHb made it necessary here to reduce with sodium hydrosulphite and estimate the $\mathrm{SHb}$ using $\mathrm{CO}$ derivatives (Lemberg et al. (1942). ) The observed SHb levels in these two 


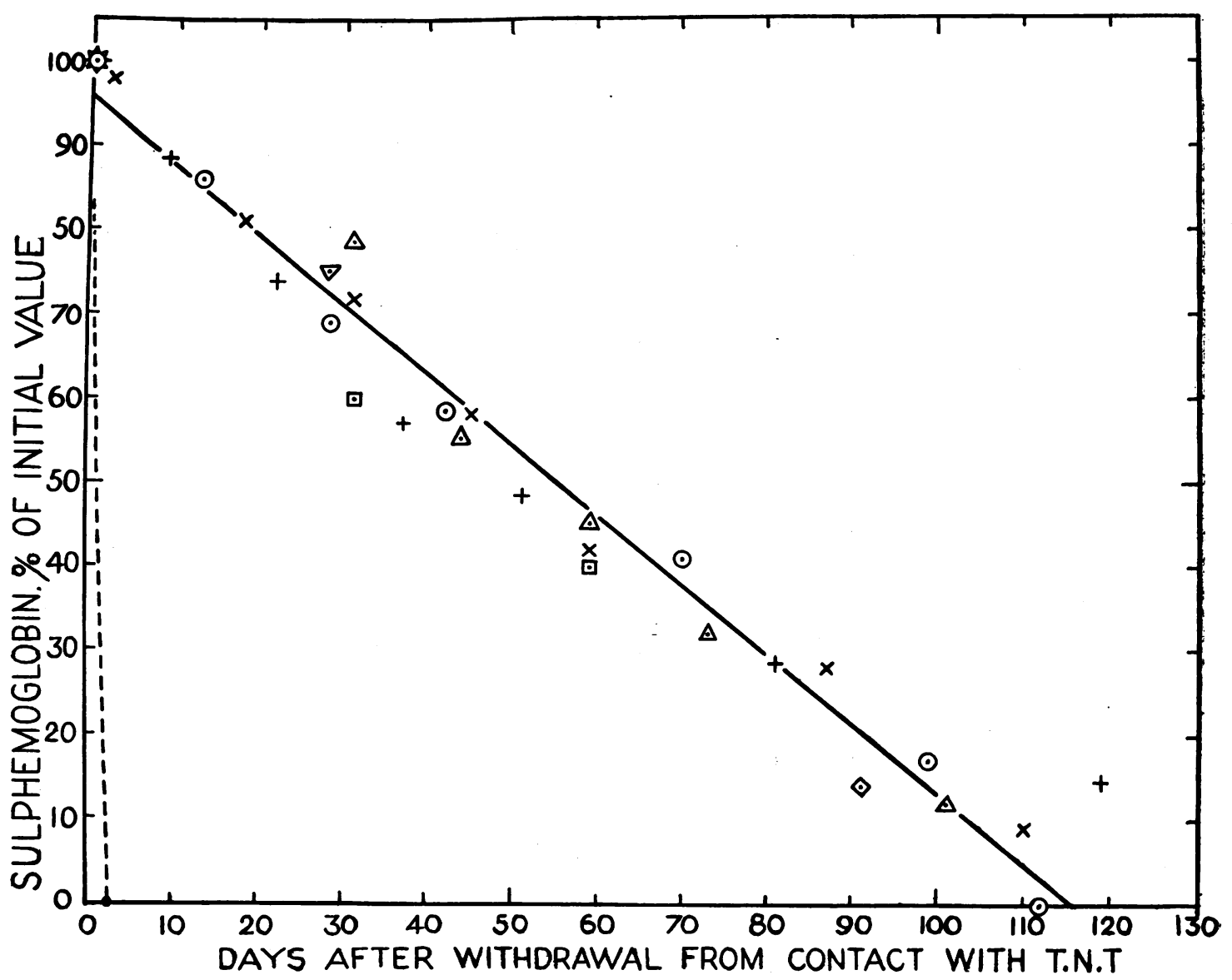

FIG. 2.-Disappearance of Sulphemoglobin and Methemoglobin from the blood of TNT workers after withdrawal from contact. The different representations of points along the Sulphemoglobin curve correspond to the seven different workers studied. Sulphəmoglobin. - - - - Methemcglobin.

cases remained as constant as could be expected under such conditions (Table 1). With further experience, and perhaps the addition of glucose to the red cell suspensions it might be possible to improve the quality of results from this type of experiment.

TABLE 1

THE STABILITY OF SULPHEMOGLOBIN AT $37^{\circ} \mathrm{C}$. in vitro.

\begin{tabular}{|c|c|c|c|c|}
\hline Days & 0 & 2 & 5 & 10 \\
\hline $\begin{array}{l}\text { SHb (per cent. of } \\
\text { total pigment) }\end{array}\left\{\begin{array}{l}\text { I. } \\
\text { II. }\end{array}\right.$ & $\begin{array}{l}7 \cdot 2 \\
5 \cdot 0\end{array}$ & $\begin{array}{l}7 \cdot 2 \\
5 \cdot 0\end{array}$ & 6.9 & $\begin{array}{l}7 \cdot 5 \\
5 \cdot 8\end{array}$ \\
\hline
\end{tabular}

\section{Life Span of the Red Cell}

\section{Discussion}

The greatest significance of these results lies in the connection between the disappearance of SHb and the destruction of the red cells which contain it. In relating these the following assumptions must be made :

(1) That the intact red cell possesses no means of changing $\mathrm{SHb}$, and that the body has no means of removing it other than removal of the red cells which contain it.

(2) That no significant SHb formation goes on after administration of the apparent causative agent is stopped.

(3) That neither SHb nor the heme part of its molecule are incorporated into new red cells.

In relating the destruction of the red cells containing SHb with that of normal red cells, two further assumptions must be made :-

(1) That the SHb formed is initially distributed at random among the red cells of all ages existing in the body at that time.

(2) That the formation of SHb within the cell does not prolong or curtail its life.

It is difficult to verify assumption (1) directly. The experiments on storing blood containing SHb formed in vivo reported above, as far as they go show that naturally formed SHb is stable under sterile conditions both in red cells and in hemolysed solutions, but working at body temperature it is not possible to make such experiments last much more than a week. Moreover, red cells can hardly 
be considered as existing reasonably unchanged for more than a day or so when whole blood is stored at body temperature. At lower temperatures the result would be hardly applicable here. The best test of assumption (1) probably results from a comparison of the forms of curves given by the differential agglutination and the marked nitrogen techniques (see below p.140), with those found for the disappearance of $\mathrm{SHb}$ in such conditions as hemolytic anaemias, etc. (e.g. Brown, Hayward, Powell and Witts (1944)).

Assumption (2) requires detailed. study ( $c f$. Cox and Wendel (1942) for MHb). By plotting in detail the SHb levels in animal experiments just before and after time $=0$ (fig. 2), more information should be obtainable concerning the formation of SHb by various compounds, and the extent to which the point $t=0$ is made uncertain due to continued formation of $\mathrm{SHb}$ by the toxic agent or a metabolite remaining in the body after administration is stopped might be assessed. However, this uncertainty of zero probably does not extend over more than a few days, and is perhaps comparable to the uncertainty of zero of the differential agglutination experiments on normal human subjects so far reported by Callender, Powell and Witts (1945), where they used donor's blood anything from 0 to 6 days old. The rapid disappearance of $\mathrm{MHb}$ from the human system on cessation of TNT (fig. B), may be significant in this connection, though it cannot be assumed that $\mathrm{SHb}$ and $\mathrm{MHb}$ are formed by the action of the same metabolic products of TNT and other toxic agents, and TNT or its metabolic products may be stored in the tissues for longer periods after prolonged contact.

Recent evidence shows that both the protein (Robscheit-Robbins et al. (1943): Whipple (1944)), and the heme (Bloch and Rittenberg (1945): Shemin and Rittenberg (1945)) of hemoglobin are formed from simple precursors during the maturation of the red cell, and there is no evidence to suggest that assumption (3) should be regarded as untrue.

Assumption (4) is also unsusceptible of simple proof. A single red cell containing 5 per cent. of its hemoglobin in the form of $\mathrm{SHb}$ would exhibit a SHb spectral absorption band at $620 \mathrm{~m} \mu$ of optical density of the order $\mathbf{0 . 0 0 5}$, or an absorption of about 1 per cent. of the incident light, which could be measured by the methods devised by Caspersson (1936: 1940), but following the distribution of SHb between red cells in this manner over a long period would be a laborious process.

Assumption (5) must be regarded as reasonable as the formation of abnormal pigment within a red cell might be expected to curtail rather than lengthen its life, and in fact the life span derived from the present study is considerably longèr than that derived from most earlier methods which were until recently generally accepted.

The obsèrvations of SHb level against time derived from these seven TNT workers are well fitted by the straight line $\mathrm{SHb}=96-0.83 t$. If the above assumptions are correct, it will be seen from the mathematical treatment of red cell survival set out by Callender, Powell and Witts (1945) which is exactly applicable here, that the value of $t$ at $\mathrm{SHb}=0$ is $116( \pm 5)$ days, and this represents the average life span of the red cell as indicated by the SHb method. These conclusions as to the life of the red cell and the linearity of decay are in close agreement with those of Callender, Powell and Witts (1945), who found an average total life span of about 120 days. Recently also Shemin and Rittenberg (1945) have studied the incorporation of the $\mathrm{N}^{15}$ isotope from ingested glycine into the protoporphyrin of hemoglobin, and have concluded that the life span of the red cell must be greater than 100 days. Their data appear to be consistent with the linear decay curves described above. It is greatly to be hoped that these workers will repeat this experiment and continue it long enough (160 days) to provide a further test of the conclusion that the life span of the red cell is about 120 days.

Variations in rates of formation or destruction of red cells will affect the linearity of the observed decay curve, and may lead to a curvature or a sawedged character according as there is a regular drift or an erratic variation. Such erratic variation may possibly be operating in the case of the man of 60 whose hemoglobin was low (p. 136 and $\Delta$ in fig. 2), but is hardly sufficient to affect greatly the general conclusions.

The observed linear decay implies that red cells have a fixed life within small limits and are not subjected to random destruction, which would lead to a logarithmic curve of decay. There are, however, indications from each of the above three experimental approaches that a small amount of random destruction may go on even in normal individuals. Callender, Powell and Witts attributed the slight curvature of the early portions of two of their normal curves to disturbances following transfusion, which is probably correct. In the $\mathrm{SHb}$ results the true $\mathrm{SHb}$ disappearance curve must clearly cut the $t=0$ axis at $\mathrm{SHb}=100$, whereas the calculated regression line cuts at $\mathrm{SHb}=96$, thus suggesting a slight curvature, though the results are unfortunately hardly sufficient to warrant more elaborate analysis. In Shemin and Rittenberg's experiment the curve for ' atom per cent. $\mathrm{N}^{15}$, against time reaches a maximum after 33 days, and the linear hypothesis requires that it then shall have a flat top until 120 days, or whatever the life span of the red cell should be, and then descend rapidly, reaching zero once more after about 150 days. Their results indicate that the top has in fact a slight negative slope, which might be due to some random destruction of red cells. Shemin and Rittenberg appear to be satisfied that no interchange of $\mathrm{N}^{15}$ takes place between the protoporphyrin and other molecules. These are all, however, only slight deviations from linearity, and in general the linear decay curve implying a fixed red cell life of about 120 days seems well established by these three experimental approaches. 
The Differential Agglutination and Sulphemoglobin methods are complementary: in the former destruction of normal red cells can be followed, but not that of the subject's own cells, while in the latter the destruction of the subject's own red cells is followed, though having $\mathrm{SHb}$ formed within them they cannot be regarded as perfectly normal. Moreover, the Agglutination method is based upon a property of the cell envelope, and the Sulphemoglobin method upon a property of the cell contents. It is therefore particularly significant that they should lead to a similar result.

The three approaches discussed above, moreover, all give information concerning the dynamics of red cell destruction, whereas most earlier approaches to the problem of red cell life merely yield an estimate of the average life with no information as to the shape of the decay curve.

Most other methods which have been used or estimating red cell life have given much shorter times-30 to 50 days in man. These have been critically reviewed recently (Callender, Powell and Witts (1945): Lancet (1945): British Medical Journal (1946) ), and only a few remarks need be added here. Assuming that it is possible to estimate the in vivo reticulocyte maturation time from observations in culture solutions (Barr and Lloyd (1943)), it would only be possible to derive an estimate of red cell life from this if the average value for the reticulocyte count were based upon a statistical study over a considerable time, which does not so far appear to have been attempted. Estimates of red cell life based on the estimation of excreted pyrrole pigments arising from the breakdown of hemoglobin are subject to uncertainty whether all the pyrrole portion of the heme of hemoglobin from destroyed red cells is transformed into a form which can be determined, to great difficulties of estimation, and also to the hitherto undefined contribution from the breakdown of the muscle hemoglobin, which forms a considerable portion of the total hemoglobin pigment of the body.

It would be most valuable to apply the $\mathrm{SHb}$ method to following the destruction of red blood cells in animals, where the blood sub-groups are not specific enough for the differential agglutination technique to be used. It appears that SHb can be produced with some certainty in the rabbit or rat by feeding with acetanilide or phenacetin (Michel (1938) : Lemberg et al. (1942) ), but that choleglobin may be formed simultaneously in amounts which might be sufficient to confuse the interpretation of the data. This choleglobin formation is especially marked with large doses of acetanilide given over a short period with the intention of producing sudden high concentrations of SHb, and hence a sharp point $t=0$ on the SHb disappearance curve. In human clinical sulphemoglobinemia only negligible amounts of choleglobin are normally encountered: it is possibly produced under milder conditions and removed nearly as fast as it is formed, for it seems that choleglobin can be transformed intracellularly. In animal experiments it would be necessary to use a precise spectrophotometric method for estimation of SHb in order to eliminate interference from choleglobin.

\section{Recovery from Cyanosis}

If cyanosis is due to $\mathrm{MHb}$ as much as $\mathbf{3 5}$ per cent. of the total blood pigment may be in a non-oxygen carrying form, but recovery after removal of the causative agent is effected rapidly by the reducing enzyme systems within the red cells. This may be complete in slight cases in 24 hours, and in more severe cases in 4 or 5 days. It has already been pointed out (Rimington (1943)) that MHb cyanosis should perhaps be regarded more seriously than the mere fraction of blood pigment immobilized would suggest, as Darling and Roughton (1942) have shown that $\mathrm{MHb}$ affects the dissociation curve for $\mathrm{HbO}_{2} \rightleftharpoons \mathrm{Hb}+\mathrm{O}_{2}$ in a manner similar to the effect of HbCO (Douglas, Haldane and Haldane (1912) ), making the oxygen less available to the tissues.

In cyanoses due to $\mathrm{SHb}$ rarely more than 7 per cent of the blood pigment is immobilized, but the effect of $\mathrm{SHb}$ on the dissociation curve of the remaining $\mathrm{HbO}_{2}$ has not so far been studied. Although the amounts of SHb encountered are slight, the present work shows that it is over three months before it is completely eliminated from the system : it would, therefore, be of value to have a more precise knowledge of any probable toxic effects it may exert. SHb is more effective in producing the impression of cyanosis than a similar amount of $\mathrm{MHb}$, as its absorption in the red is greater than that of $\mathrm{MHb}$.

It must be emphasized that in order to distinguish between cyanoses produced by $\mathrm{MHb}$ and $\mathrm{SHb}$ careful measurements must be made on a good spectroscope, for instance, a Hartridge reversion spectroscope. If the wavelength calibration is inadequate the stability of SHb (band at $620 \mathrm{~m} \mu$ ) to reagents such as KCN (carefully neutralized) and sodium hydrosulphite may be used to distinguish it from $\mathrm{MHb}$, whose $635 \mathrm{~m} \mu$ band disappears with these reagents. With good illumination in a Hartridge spectroscope using a $1 / 4$ dilution of blood in a $2 \mathrm{~cm}$. layer about 3 per cent. of $\mathrm{MHb}$ and about 1 per cent. of SHb can be detected by their bands at $635 \mathrm{~m} \mu$ and $620 \mathrm{~m} \mu$.

In our experience with TNT we have encountered about one case showing $\mathrm{SHb}$ to 40 showing $\mathrm{MHb}$ (Jope and O'Brien (1942)).

After all the cyanoses which we have been able to account for by the presence of $\mathrm{MHb}$ and $\mathrm{SHb}$, and the few subsequently discovered to be suffering from a lung or heart complaint, there still remain some in which no abnormal pigment can be demonstrated, thus confirming the finding of Horecker (1944) and others. This has sometimes been thought to be due to a pigment, possibly a combination of a metabolite of the toxic agent with hemoglobin ( $c f$. Keilin and Hartree 1943)), which immediately splits up on dilution. Examination on the spectrograph of thin films of red cells in some 
such cases has failed to show up any spectral absorption bands in the red, and cyanosis was therefore probably due in those cases to excessive amounts of reduced hemoglobin in the peripheral blood vessels. The toxic agent or metabolite might well itself affect the $\mathrm{O}_{2}$ dissociation curve of $\mathrm{HbO}_{2}$, and this point might profitably be investigated. However, a loose compound between a metabolite of the toxic agent and the $\mathrm{Hb}$, with a spectral absorption band on the red may well occur in some other cases.

\section{Summary}

(1) Whereas methemoglobin is removed from the circulating blood by intracellular reducing enzymes in 2 to 5 days after a TNT worker is taken off contact, Sulphemoglobin persists for about 116 days.

(2) The disappearance of sulphemoglobin from the blood of seven TNT workers has been related to the destruction of the red blood cells which contain it, the necessary assumptions being discussed. A linear decay is found, disproving random destruction and indicating that the red cell has a fixed life-span. This is estimated at 116 days. These conclusions are in agreement with other recent work.

(3) Possible applications of this method of studying the dynamics of red cell destruction are discussed.

(4) Recovery from cyanosis is discussed.

\section{Acknowledgments}

I wish to thank Dr. A. J. Amor, at the time Chief Medical Officer, Ministry of Supply, for arranging that this work could be undertaken at a Ministry of Supply factory, and for his encouragement throughout, and also Drs. H. K. Tucker and Helen Ramsay for their kindness and co-operation in despatching blood samples and providing clinical notes during the experiment.

The majority of the work reported here was carried out during my tenure of a personal grant from the Medical Research Council. I am par- ticularly grateful to Dr. E. R. Holiday for much advice and discussion, and for the use of much of the equipment he has designed. Preliminary studies on which some of this paper is based were carried out in the department of Biochemistry, Oxford, with Mr. J. R. P. O'Brien and my wife, to both of whom I am grateful. I wish also to thank Professors L. J. Witts and C. Rimington and Drs. K. M. A. Perry, F. C. O. Valentine and H. Hoch for helpful discussions.

\section{REFERENCES}

Austin, H. J., and Drabkin, D. L. (1935). J. Biol. Chem., 112, 67.

Bustin, H. S., and Lloyd, T. W. (1943) Bloch, K., and Rittenberg, D. (1945). J. Biol. Chem., 159, 45. (footnote i)

British Medical Journal, (1946) Leading Article, 1576.

Brown, G. M., Hayward, O. C., Powell, E. O., and Witts, L. J. (1944). J. Path. Bact., 56, 81 .

Callender, S. T., Powell, E. O., and Witts, L. J. (1945). J. Path. Bact., 57, 129

Caspersson, T. (1936). Acta Skand. Physiol., Suppl. 73, No. 8,

Caspersson, T. (1940). J. Roy. Microscop. Soc., 50, 8

Cox, W. W., and Wendel, W. B. (1942). J. Biol. Chem., 143, 331. Darling, R. C., and Roughton, F. J. W. (1942). Am. J. Physiol., 137. 56.

Douglas, C. G., Haldane, J. B. S., and Haldane, J. S. (1912). J. Physiol., 44, 275.

Drabkin, D. L. (1945). Science, 101, 445.

Drabkin, D. L., and Austin, J. H. (1935). J. Biol. Chem., 112, 51.

Haurowitz, F. (1940). J. Biol. Chem., 137, 771

Horecker, B. L. (1944). U.S. Public Health Bull. No. 285, 46.

Jope, E. M. (1941). B.Sc. Thesis, Oxford

Jope, E. M., Jope, H. M., and O'Brien, J. R. P. (1944). To be

Jope, E. M., and O'Brien, J. R. P. (1942). To be published.

Jope, E. M., O'Brien, J. R. P., and Watson, J. (1942). Report to Ministry of Supply Medical Officers, Nov. 1942.

Keilin, D. (1933). Proc. Roy. Soc. Lond., B, 113, 393.

Keilin, D., and Hartree, E. F. (1943). Nature, 151, 390.

Lemberg, R., Holden, H. F., Legge, J. W., and Lockwood, W. H. (1942). Austral. J. Exptl. Biol. Med. Scl., 20, 161.

cfarlane, R. G., O'Brien, J. R. P., et al. (1944). Brit. Med. J.,

Michel, H. O. (1938). J. Biol. Chem., 126, 323.

Robscheit-Robbins, F. S.. Miller, L. Lem., 12, 427. J. Exptl. Med., 77, 375.

Shemin, D., and Rittenberg, D. (1945). J. Biol. Chem., 159, 567.

Warburg, O., Kubowitz, F., and Christian, W. (1930: 1931). Bioch. Warburg, O., Kubowitz, F., and Christian, W. (1930 : 1931)
Z., 221, 494; 227, 245; 233, 240; 234, 107; 242, 170.

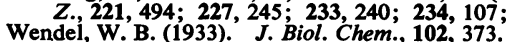

Wendel, W. B. (1933). J. Biol. Chem., 102, 